\title{
Follow-Up Study of Private Well Users Affected by Groundwater Arsenic in the Surrey-Langley Area
}

\author{
Douglas Gordon ${ }^{1}$, Marc Zubel ${ }^{2}$, Blair Choquette ${ }^{3}$, Helen Heacock ${ }^{4}$
}

1 Lead Author, B. Tech Student, Environmental Health Program, School of Health Sciences, British Columbia Institute of Technology, 3700 Willingdon Ave, Burnaby, BC V5G 3H2

2, 3 Supervisors, Fraser Health Drinking Water Program, Health Protection Office, \#207-2776 Bourquin Crescent W, Abbotsford, BC V2S 6A4

4 Supervisor, School of Health Sciences, British Columbia Institute of Technology, 3700 Willingdon Ave, Burnaby, BC V5G $3 \mathrm{H} 2$

\section{Abstract}

Background: Arsenic is a potent toxicant and Group 1 human carcinogen which occurs naturally in certain sediments and can contaminate groundwater. In the Surrey-Langley area of British Columbia, a 2007 study of private wells found that $43 \%$ of wells tested contained arsenic concentrations above the maximum acceptable concentration (MAC) prescribed in Health Canada's Guidelines for Canadian Drinking Water Quality. The well owners who participated in the 2007 study were informed of the results and of effective treatment methods that would remove the arsenic contamination. This is a follow-up study that surveyed affected well users approximately 10 years later in order to identify whether the well users had subsequently made any water treatment or behavioral changes to improve the quality of their drinking water, and also to determine whether knowledge translation of the arsenic risk had been effective.

Methodology: This study contacted and enrolled private well users who were living at properties which had previously been included in the 2007 study and, in 2007, were found to have arsenic levels above the MAC in the groundwater. Respondents who agreed to participate completed a questionnaire designed to identify what treatment methods or behavioral methods they use to mitigate the risk posed by arsenic contamination. Pre-treatment and post-treatment samples of their drinking water were collected and the arsenic concentrations were analyzed. The effectiveness of treatment devices for arsenic removal was evaluated. The groundwater arsenic concentrations from approximately 10 years apart were compared to identify if arsenic levels had changed.

Results: Of the 42 properties that participated in the 2007 study and had groundwater arsenic levels above the MAC, 17 participated in this follow-up study. 14 of the participants also took part in the 2007 study 10 years ago. 79\% of participants had not known prior to taking part in the 2007 study that their drinking water contained arsenic levels above the MAC. All $79 \%$ then either installed reverse osmosis treatment devices to remove arsenic from their drinking water, or switched to using bottled water for drinking. This indicates that knowledge translation of the health risk was effective. Of the 8 properties using treatment devices rather than bottled water, to mitigate the arsenic risk, $2 / 8(25 \%)$ were ineffective at reducing arsenic. In addition, arsenic groundwater concentrations were not found to have changed significantly in 10 years $(p=0.11)$.

Conclusion: Participation in the 2007 study was viewed as useful and informative by participants. Knowledge translation of the health risk and the need for risk mitigation was effective, but $25 \%$ of treatment devices were found to be ineffective at removing arsenic from drinking water. These results suggests that further knowledge translation of the need for routine testing for arsenic in post-treated drinking water may be beneficial to affected private well users.

Keywords: arsenic, groundwater, knowledge translation, private well users, Surrey, Langley 


\section{Introduction}

This is a follow-up study to a study performed in 2007 by Julie Wilson, Hans Schreier and Sandra Brown of the Institute for Resources \& Environment at The University of British Columbia, for Fraser Health Authority and the BC Ministry of Environment (which will henceforth be referred to as "the 2007 study") [1]. The 2007 study tested the pre-treatment water from 98 private wells in the SurreyLangley area and found that the water from 42 of the wells contained elevated arsenic levels. This follow-up study returned to 17 of the original 42 properties approximately 10 years later, in order to determine whether knowledge translation of the health risk had been effective, and whether the well owners had subsequently made any water treatment changes or behavioral changes to improve the quality of their drinking water.

Aims:

- To assess whether participation in the 2007 study effectively translated the severity of the arsenic health risk, and the need for effective drinking water treatment, to participants;

- To determine what information was provided to any new property occupants who had moved into the properties after the 2007 study was completed;

- To evaluate if the treatment devices being used were effective at reducing arsenic levels below the maximum acceptable concentration (MAC) in the Guidelines for Canadian Drinking Water Quality;

- To compare groundwater arsenic concentration data from the follow-up study with data from the 2007 study to determine if arsenic concentrations have increased or decreased over time.

\section{Evidence Review}

Sources and distribution of groundwater arsenic

Arsenic is a metalloid and is ubiquitous in the environment. It is the 20th most common element in the Earth's crust ${ }^{[2]}$, with an average terrestrial abundance of approximately 5 parts per million ${ }^{[3]}$. Arsenic is mobilized in the environment through natural processes, such as the weathering and erosion of Arsenic-rich rocks and soil, biological activity and volcanic emissions. Most environmental arsenic problems are caused by natural processes, although arsenic mobilization is also caused by anthropogenic activities, such as leaching from current and former goldprocessing sites, the use of arsenical pesticides and wood preservatives, emissions from coalfired power plants, and the disposal of both industrial and domestic wastes ${ }^{[4]}$.

Of the various sources of arsenic in the environment, arsenic contamination of drinking water poses the greatest threat to human health. Worldwide, at least 130 million people across the globe have been, or are exposed to, levels of arsenic in their drinking water exceeding the World Health Organization limit of $0.010 \mathrm{mg} \mathrm{L}^{-1}$ [5]. National level data on groundwater arsenic occurrence in Canada is limited, but most provinces and territories report some areas where arsenic can be detected in private drinking water supplies. Documented hotspots with concentrations of arsenic above $0.010 \mathrm{mg} \mathrm{L}^{-1}$ have been reported in southern British Columbia, Alberta, Manitoba, north-eastern Saskatchewan, New Brunswick, Newfoundland and Labrador and Nova Scotia ${ }^{[6]}$.

In the Lower Fraser Valley region of British Columbia, where this study was undertaken, the arsenic is of natural origin and is associated with marine and glaciomarine sediment deposits. It is predominantly found in deep wells, in aquifers which are classified as confined and of low vulnerability ${ }^{[7]}$. 
Health effects of oral arsenic exposure

Arsenic is a potent toxicant and is classed as a Group 1 human carcinogen by The International Agency for Research on Cancer. Arsenic may exist in several oxidation states and in a number of inorganic and organic forms, although most cases of arsenic-induced toxicity in humans are due to exposure to inorganic arsenic. Acute, high-dose exposure to inorganic arsenicals have been reported to cause nausea, vomiting, diarrhea, and abdominal pain, although the specific doses associated with the onset of these symptoms have not been identified ${ }^{[8]}$. The acute lethal dose for arsenic has been estimated to be about $0.6 \mathrm{mg} \mathrm{kg}^{-1} \mathrm{day}^{-1}{ }^{[8]}$.

The adverse health effects resulting from chronic, low-dose oral exposure to inorganic arsenic is an area of ongoing research. The greatest strength of evidence for a causal association between arsenic and adverse effects is for cancers of the skin, bladder and lung, and for skin lesions (hyperkeratosis, hyperpigmentation and hypopigmentation). Causal associations have been observed in studies where the levels of arsenic in drinking water exceeded $0.1 \mathrm{mg} \mathrm{L}^{-1}$. At lower concentrations of arsenic, and at different sites in the body (including the prostate, liver and kidney), the evidence for disease causation is less conclusive ${ }^{\text {[9]. Oral }}$ arsenic exposure has also been demonstrated to have an association with hypertension ${ }^{[10]}$.

Besides the epidemiological results on the association between arsenic exposure and somatic disorders, there are also some findings indicating an association between arsenic exposure and elevated risk for psychiatric disorders, including anxiety, depression and suicidal behavior ${ }^{[10]}$. The most recent report provided by the Agency for Toxic Substances and Disease Registry ${ }^{\left[{ }^{8]}\right.}$ has suggested that toxic exposures to arsenic may result in memory loss and emotional instability in humans. Epidemiological studies from the past decade have shown a strong correlation between arsenic exposure and neurological and cognitive dysfunction in children and adults ${ }^{[11]}$.

To predict the impact on Canadian populations exposed to arsenic through drinking water, The Federal-ProvincialTerritorial Committee on Drinking Water have estimated the excess lifetime risk of internal organ cancers (lung, bladder and liver). Their estimates are summarized below in Table 1.

\begin{tabular}{|c|c|}
\hline $\begin{array}{c}\text { Level of Arsenic } \\
\text { in Drinking } \\
\text { Water }\left(\mu \mathrm{g} \mathrm{L}^{-1}\right)\end{array}$ & $\begin{array}{c}\text { Estimated Lifetime } \\
\text { Range of Risk of } \\
\text { Excess Internal } \\
\text { Organ Cancers (x } \\
\left.10^{5}\right)\end{array}$ \\
\hline 0.3 & $\begin{array}{c}0.09-1 \\
\text { ("essentially } \\
\text { negligible risk") }\end{array}$ \\
\hline 5 & $2-20$ \\
\hline 10 (MAC) & $3-39$ \\
\hline 25 & $8-97$ \\
\hline
\end{tabular}

Table 1: Estimated lifetime range of risk of excess internal organ cancers (in addition to the background lifetime cancer risk) associated with various concentrations of arsenic in drinking water (modified from: Guidelines for Canadian Drinking Water Quality: Arsenic Guideline Technical Document ${ }^{[12]}$ )

Table 1 shows the number of excess incidences of internal organ cancers that would be expected for a population of 100000 people exposed to drinking water arsenic for 70 years (an estimated lifetime). A concentration of $0.3 \mu \mathrm{g} \mathrm{L}^{-1}$ (or 300 parts per trillion) of arsenic in drinking water is considered "essentially negligible", as if a population of 100000 people were exposed for 70 years, only 1 excess case of internal organ cancer would be expected to occur. Based on these risk estimates, and on feasibility considerations, Federal-ProvincialTerritorial Committee also set a Maximum Acceptable Concentration for drinking water of $0.010 \mathrm{mg} \mathrm{L}^{-1}$. This is the maximum level of arsenic that should be present in municipal and residential drinking water, after treatment has been performed. The Committee also stated 
that every effort should be made to reduce arsenic levels to as low as reasonably achievable ${ }^{[12]}$.

Previous studies of knowledge translation of the risk posed by arsenic to private drinking water

Knowledge translation is defined by The Canadian Institutes of Health Research as "a dynamic and iterative process that includes synthesis, dissemination, exchange and ethically sound application of knowledge to improve the health of Canadians, provide more effective health services and products and strengthen the health care system" ${ }^{[13]}$. This evidence review found that very few studies of either private well owners' awareness of arsenic contamination, or of the effectiveness of knowledge translation of the risk posed by arsenic, had been performed in North America. This is likely due to the minimal regulatory oversight that the Canadian and United States' governments have over private wells.

One study of well owner knowledge surveyed 525 private well owners in central Maine, and found that $22 \%$ of households had not been testing their wells for any chemical or microbiological parameters. Of the $78 \%$ who tested their wells, half of them had last tested more than 5 years ago. Among the $58.7 \%$ who believed they have tested for arsenic, most did not remember results ${ }^{[14]}$.

A similarly low frequency of testing for arsenic was seen in results from a survey of 420 private well owners in Nova Scotia. When asked how frequently they performed chemical testing (which includes arsenic as a parameter), only $12 \%$ of respondents tested once every two years or more, as per the Nova Scotia Environment Department guideline. $50 \%$ of the respondents reported testing for chemical contaminants 'irregularly' and 29\% reported testing 'only once ever' ${ }^{[15]}$.

Infrequent testing by private well owners may be an intentional choice in some circumstances, as the discovery of arsenic contamination of groundwater can cause a devaluation of the property where it is found and a devaluation of other properties in neighborhood. A study of two towns in Maine found an arsenic hotspot where $14 \%$ of private wells were affected by arsenic concentrations that exceeded the EPA standard. When this discovery was publicized, it caused a 3 year decrease in property prices in the area ${ }^{[16]}$.

\section{Methodology}

Cover letters explaining the purpose and scope of the study, and requesting participation, were created and mailed to occupants of the 42 properties identified in the 2007 study as having groundwater arsenic levels above the MAC. Occupants of 11 of the 42 properties responded to the cover letter agreeing to take part in the study. They were contacted by telephone, and sampling was performed at their property at a date and time that was convenient for them. The remaining 31 properties were visited unannounced at a reasonable time (between the hours of 10:00 and 17:00 on weekdays). On unannounced visits, the study cover letter was used to explain the purpose of the visit, and the free arsenic testing being offered was emphasized in order to incentivize enrolment.

Each Participant filled-out a printed copy of a survey questionnaire. The survey questionnaire was developed to yield answers that would meet the study's aims. It was designed to be short (taking less than five minutes to complete), and to be readily understandable to people who did not possess a technical knowledge of the health risks associated with arsenic or well water treatment methods. 
Participants also gave their permission for their water to be sampled. Water samples were collected according to a protocol established by Exova Laboratory (a CAN-P-

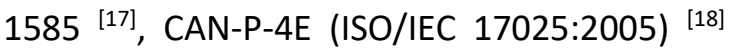
accredited laboratory), and refrigerated in a cooler. At properties where a water treatment device was used, pre-treatment samples and post-treatment samples were collected. Pretreatment samples were taken from a tap or spigot located before the treatment device within the plumbing system, and posttreatment samples were taken from a tap or spigot located after the treatment device. At properties were no treatment device was used, only one un-treated sample was taken. Samples were delivered to Exova Laboratory for extractable arsenic testing on the same day as they were collected.

The survey questionnaires answers data and the results from the extractable arsenic testing were collated. Letters explaining the arsenic testing results were mailed to the participants. Participants were informed of the concentration of arsenic that was present in their water sample(s), and, if they had a treatment device, whether device was currently effectively removing the arsenic. Two of the participant's results indicated that their reverse osmosis treatment devices were not reducing the arsenic concentration. They were contacted by the drinking water officer who informed them of the possible health hazard, and recommended that they contact a water treatment company to determine what was needed.

\section{Study area}

The study area encompassing the 42 properties covers the Township of Langley and the lowland portion of Surrey. The area extends from the US-Canada border to the Fraser River. A map of the area is provided in Figure 1.

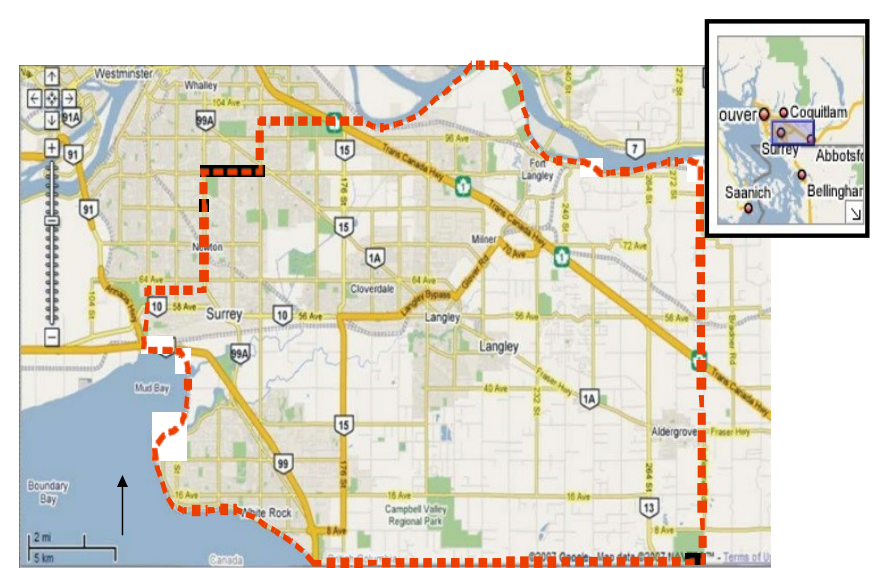

Figure 1. Map of Surrey-Langley region. Study area enclosed by red line. (modified from Wilson J, Schreier $\mathrm{H}$, Brown S. Arsenic in Groundwater in the Surrey-Langley Area ${ }^{[1]}$ ) (C) 2017 Google

\section{Results and Discussion}

\section{Scope of study and study population size}

This study attempted to contact and enroll 42 property occupants or owners in the Surrey-Langley area. The occupants of 17 different properties agreed to participate, which roughly equates to a $40 \%$ response rate. By contrast, in the 2007 study, a total of 486 letters were sent out requesting enrolment, and a total of 98 responses agreeing to be participants were received. This equated to approximately a $20 \%$ response rate. Whilst the response rate is acceptable in this study, the small sample size means that the validity of the inferences drawn from the data may be limited.

Reasons for non-participation by property occupants

The reasons that the occupants of 25 of the 42 properties included in the study did not participate are listed in Table 2. 


\begin{tabular}{|c|c|}
\hline $\begin{array}{c}\text { Reason for non- } \\
\text { participation }\end{array}$ & $\begin{array}{c}\text { Number of } \\
\text { incidences }\end{array}$ \\
\hline $\begin{array}{c}\text { Occupants not present } \\
\text { at property when } \\
\text { visited }\end{array}$ & 10 \\
\hline $\begin{array}{c}\text { Property could not be } \\
\text { located using 2007 } \\
\text { address }\end{array}$ & 5 \\
\hline $\begin{array}{c}\text { Property has switched } \\
\text { to municipal water } \\
\text { supply }\end{array}$ & 2 \\
\hline $\begin{array}{c}\text { Property is vacant/ } \\
\text { being rebuilt }\end{array}$ & 2 \\
\hline $\begin{array}{c}\text { Occupant "not } \\
\text { interested" in } \\
\text { participation }\end{array}$ & 1 \\
\hline $\begin{array}{c}\text { Occupant not available } \\
\text { during period of data } \\
\text { collection }\end{array}$ & 1 \\
\hline Language barrier & \\
\hline
\end{tabular}

Table 2. Reasons for non-participation in the study by property occupants

The most common reason was that the occupants were not present when the property was visited. A copy of the cover letter with contact information was left in the mailbox at these properties, however the occupants did not attempt to contact the study and arrange to take part. The second most common reason for non-participation was that 5 of the properties could not be located using the addresses from the 2007 study. The study administrator visited the addresses using Google Maps and a GPS navigation device, however the properties could not be found at the location given. Without further contact information it was not possible to contact the occupants of these properties for the purpose of enrolment into the study.

The most commonly stated reason that occupants gave against participation was that they were now using a municipal water supply system. Over the past 10 years municipal systems have been expanded in parts of Surrey and Langley. Areas affected by this expansion in this study include 40th Avenue in Surrey and 82nd Avenue in Langley.
As the occupants using municipal water supplies were no longer use their wells for any purpose, the elevated groundwater arsenic concentration at these properties is now no longer of public health significance. $\begin{aligned} & \text { Characterization of } 2017 \text { follow-up study } \\ & \text { population }\end{aligned}$

Tables 3 and 4 below show the age ranges and employment situations of the 17 participants in this study.

\begin{tabular}{|c|c|}
\hline Age category & $\begin{array}{c}\text { Number of } \\
\text { participants }\end{array}$ \\
\hline Prefer not to say & 0 \\
\hline $18-24$ & 0 \\
\hline $25-34$ & 1 \\
\hline $35-44$ & 1 \\
\hline $45-54$ & 1 \\
\hline $55-64$ & 4 \\
\hline $65+$ & 10 \\
\hline
\end{tabular}

Table 3. The number of study participants in each age category

\begin{tabular}{|c|c|}
\hline Employment situation & $\begin{array}{c}\text { Number of } \\
\text { participants }\end{array}$ \\
\hline Other & 0 \\
\hline Unemployed & 0 \\
\hline Student & 0 \\
\hline Prefer not to say & 1 \\
\hline Homemaker & 1 \\
\hline Working full time & 2 \\
\hline Self employed & 2 \\
\hline Working part time & 3 \\
\hline Retired & 8 \\
\hline
\end{tabular}

Table 4. The number of study participants in each employment category

As is shown in tables 3 and 4 , the majority of the participants were middle aged or older and were mostly retired, worked parttime or were self-employed. This skew towards older aged participants may be due to the way the study was administered. 31 of the 42 properties were visited unannounced, on weekdays between 10:00 am and 17:00 pm. It is therefore probable that fewer full-time employed occupants were met on these visits, and so this may have produced a bias in the 
demographic who were enrolled into the study.

Measuring the effectiveness of knowledge translation from the 2007 study

To determine the effectiveness of knowledge translation from the 2007 study, 4 different criteria have been evaluated. Firstly, participants in the original study were asked in the questionnaire for their opinion on how useful they found the information that was provided to them by the 2007 study. Secondly, they were asked whether the information they received led them to change their method of water treatment or adopt a behavioral change (such as using bottled water as their source of drinking water). Thirdly, new occupants who had moved into properties after the 2007 study had concluded were asked if they had been informed about the elevated groundwater arsenic concentration. Fourthly, the drinking water treatment devices at participating properties were tested to evaluate their effectiveness for removing arsenic.

In the opinion of the 2007 study participants, was the information they received useful?

The 2007 study alerted all 42 participants whose well water contained over $0.010 \mathrm{mg} / \mathrm{L}$ of arsenic that their well water exceed the maximum acceptable concentration in Health Canada's Canadian Drinking Water Quality Guidelines. The 2007 study provided each participant with a water quality report, and recommended that the participant contact a water treatment company to determine what would be needed to remove the arsenic. To ascertain if this was useful, the 14 participants who took part in both the 2007 study and this study were asked if the found the information useful and informative. 86\% (12/14) participants said that they did find the information useful and informative.

The participants were also asked how they first learned that their well water contained elevated levels of arsenic. 71\% $(10 / 14)$ of participants stated that they had not previously known about the presence of groundwater arsenic, and had learned of the issue because of taking part in the 2007 study. Of the remaining $29 \%$ (4/14) participants, 1 was aware of the presence of groundwater arsenic but unaware what the current MAC was or that it was being exceeded. Health Canada revised the maximum acceptable concentration down from $0.025 \mathrm{mg} / \mathrm{L}$ to 0.010 $\mathrm{mg} / \mathrm{L}$ in 2006, and this participant had not known about the change.

Did the information cause participants to change their behavior with respect to the arsenic risk?

Of the 14 participants who took part in both the 2007 study and this study, 79\% $(11 / 14)$ discovered that they had arsenic levels above the MAC of 0.010 in their well water. All $79 \%(11 / 14)$ of the participants then either installed reverse osmosis treatment devices to remove arsenic from their drinking water (these are a treatment devices which are recognized to be effective at removing arsenic ${ }^{[19][20]}$ ), or switched to using bottled water. This is a clear demonstration that the risk was effectively communicated by the study, and was taken seriously by the study participants.

The remaining $21 \% \quad(3 / 14)$ were already aware of the elevated arsenic and had pre-existing treatment that was effective at removing arsenic or were using drinking water. Therefore, all of 14 participants who took part in both the 2007 study and this study have a significant awareness of the risk of arsenic and the need for effective mitigative action. This is further evidence that knowledge translation from the 2007 study was successful.

Were new property occupants made aware of the arsenic risk?

New occupants who had moved into properties in this study after the 2007 study had concluded were asked if they had been informed about the elevated groundwater 
arsenic concentration. Only 3 new property occupants took part in this study, of whom only 1 stated how they learned about the elevated arsenic, and they were informed by the previous property owner. Of the other 2 new property occupants, 1 did not remember and 1 declined to answer the question. However, all of the new occupants effectively mitigated the arsenic risk, either by using an effective reverse osmosis treatment device, or by using bottled water for drinking.

Were the participant's treatment devices effective at reducing arsenic levels?

Pre-treatment and post-treatment arsenic concentrations were collected and analyzed for each well of the 8 properties which were using a treatment device to remove arsenic. As a group, post treatment water samples were significantly lower in arsenic than pre samples $(p=0.00521)$. However, post samples were not significantly lower than the MAC of $0.010 \mathrm{mg} \mathrm{L}^{-1}(p=0.4)$. Of the 8 treatment devices evaluated by pre and post sampling, 2 were found to be ineffective. This suggests that knowledge translation of the need for regular maintenance of treatment devices was less successful than knowledge translation of the arsenic health risk.

Have groundwater arsenic levels changed significantly in 10 years?

To identify if temporal variations in groundwater arsenic concentrations had occurred at the properties between 2007 and 2017, untreated water samples from the 17 properties in the 2017 study were compared with the untreated water data from the same properties in the 2007 study ${ }^{[1]}$. The results were not significantly different $(p=0.11)$, indicating little change in arsenic levels has occurred.

\section{Study Limitations}

Sample size

This study was a follow-up study to the 2007 study into groundwater arsenic performed at the same properties. This study was therefore limited in the number of participants that it could enroll. Of the occupants of the 42 properties, only 17 agreed to take part. An adequate sample size is usually a minimum of 30 participants, and so the sample size in this study may not be large enough to ensure that the data is truly representative of private well users in the Surrey-Langley area.

Bias

This study investigated how private well users had responded to the significant findings of the 2007 study that their well water was contaminated by elevated levels of arsenic. All of the 14 participants who took part in both the 2007 study and this follow-up study, were found to be either using an appropriate type treatment device for arsenic removal (such as a reverse osmosis unit) or were drinking bottled water. It is therefore possible that this study has a positive bias, and that only well users who had understood the risk and had taken mitigative action, agreed to take part. It is possible that one or more of the non-respondents may not have taken part in the study because they had not addressed the arsenic issue, and they therefore would not wish to take part in a study that would reveal this.

\section{Recommendations for further knowledge translation and the development of educational materials}

Of the 17 participants, 8 use bottled water for their drinking water, rather than using a treatment device. Several of the participants asked about the cost of installing and maintaining a treatment device, such as a point of use reverse osmosis unit. Health authorities in areas where groundwater 
arsenic is a frequent issue for private well users may wish to consider producing a pamphlet or similar resource that can assist private well users in deciding if treatment is affordable. Whilst all the participants in this study were aware of the arsenic and took mitigative measures to control the risk of exposure, there are likely to be well users who are unaware of the affordability of reverse osmosis units [21], and who will otherwise continue to use arsenic-contaminated water for drinking.

\section{Recommendations for future research}

This study identified one area of environmental health where there is limited existing research. Of the 9 participants who use bottled water for drinking rather than a treatment device, 4 of them continue to use their untreated water for food preparation and cooking. Whilst food preparation may not be considered a significant arsenic exposure risk, using untreated water for cooking (especially in dishes such as stews) or for boiling foods may pose an exposure risk. Cooking food items containing arsenic (such as certain types of fish) has been shown to increase the arsenic concentration of the food ${ }^{[22]}$. Further research is needed in order to determine if cooking in water containing arsenic will significantly increase the arsenic content of foods, and whether health authorities should recommend to private well users that water containing arsenic should not be used for cooking.

\section{Conclusion}

This study was a follow-up study which aimed to determine the effectiveness of knowledge translation from the 2007 study. Based on the results from this study, prior knowledge translation was effective. $71 \%$ $(10 / 14)$ of the 2007 study participants questioned in this follow-up study stated that they learned about the presence of groundwater arsenic for the first time by taking part in the 2007 study. Of the $71 \%$ (10/14) who found out about the arsenic through the 2007 study, all $71 \%(10 / 14)$ then switched to an appropriate type of treatment device, or switched to drinking bottled water, after they received the information.

Overall awareness of the arsenic risk and the need to take mitigative action was high. Every participant (17/17) was using either an appropriate type of treatment device (though not necessarily working effectively) or was drinking bottled water

Whilst previous efforts can be considered successful, this follow-up study has identified areas requiring further knowledge translation. Participants were frequently unaware of what the cost of a reverse osmosis unit would be. They had purchased bottled water for years, probably amounting to a greater overall cost than installing a simple point of use reverse osmosis unit. Also, this study identified a possible lack of awareness of private well users about the need for routine testing of their water and maintenance of their treatment devices. Two of the 8 treatment devices which were tested in this study for their ability to reduce arsenic were found to be ineffective. This equated to $25 \%$ of the devices tested in this study. This suggests that private well users need further guidance on how maintain their devices through regular testing and servicing.

\section{Acknowledgements}

The lead author would like to thank Helen Heacock, Marc Zubel and Blair Choquette for their guidance, support and patience. The lead author would also like to thank Martin McLeod for his advice and contributions to the survey questionnaire.

\section{Competing Interest}

The authors declare that they have no competing interests.

\section{References}

[1] Wilson J, Schreier H, Brown S. Arsenic in Groundwater in the Surrey-Langley Area For: Environmental Health Services. 2008. [Cited 27th April 2017] Available from: 
https://www.fraserhealth.ca/media/ArsenicR eportSurreyLangley.pdf

[2] Mandal B. Arsenic round the world: a review. Talanta. 2002;58(1):201-35. [Cited 27th April 2017] Available from: http://www.science.marshall.edu/murraye/Ar senic\%20Around\%20the\%20World.pdf

[3] The International Agency for Research on Cancer Working Group 2006. Arsenic and Arsenic compounds. IARC Monograph 2006;: 41-94. [Cited 27th April 2017] Available from: http://monographs.iarc.fr/ENG/Monographs/ vol100C/mono100C-6.pdf

[4] Smedley P, Kinniburgh DG. Essentials of Medical Geology - 1st Edition. Chapter 1: 1 61. [Cited 27th April 2017] Available from: http://www.who.int/water_sanitation_health /dwq/arsenicun1.pdf

[5] Peter Ravenscroft, Hugh Brammer KR. Arsenic Pollution: A Global Synthesis [Internet]. Wiley-Blackwell; 2009. [Cited 27th April 2017] Available from: http://onlinelibrary.wiley.com/book/10.1002/ 9781444308785

[6] McGuigan CF, Hamula CL a., Huang S, Gabos $S$, Le XC. A review on arsenic concentrations in Canadian drinking water. Environ Rev. 2010;18(October):291-307. [Cited 27th April 2017] Available from: https://www.jstor.org/stable/envirevi.18.291

[7] Wilson JE, Brown S, Schreier H, Scovill D and Zubel M. Arsenic in Groundwater Wells in Quaternary Deposits in the Lower Fraser Valley of British Columbia, Canadian Water Resources Journal / Revue canadienne des ressources hydriques, 33:4, 397-412. [Cited 27th April 2017] Available from: http://dx.doi.org/10.4296/cwrj3304397

[8] U.S. Department of Health and Human Services Agency Toxic Substances and Disease Registry. Toxicological profile for arsenic. [Cited 27th April 2017] Available from: https://www.atsdr.cdc.gov/toxprofiles/tp2.pd f
[9] JECFA. Safety evaluation of certain contaminants in food [Internet]. Vol. 82, FAO food and nutrition paper. 2011. 1-778. [Cited 27th April 2017] Available from: http://apps.who.int/iris/bitstream/10665/445 20/1/9789241660631_eng.pdf\%5Cnhttp://w ww.ncbi.nlm.nih.gov/pubmed/17340910

[10] Abhyankar LN, Jones MR, Guallar E, NavasAcien A. Arsenic exposure and hypertension: A systematic review. Environ Health Perspect. 2012;120(4):494-500. [Cited 27th April 2017] Available from: https://ehp.niehs.nih.gov/1103988/

[11] Tyler CR, Allan AM. The Effects of Arsenic Exposure on Neurological and Cognitive Dysfunction in Human and Rodent Studies: A Review. Current Environmental Health Reports. 2014;1(2):132-147. [Cited 27th April 2017] Available from: https://www.ncbi.nlm.nih.gov/pmc/articles/P MC1742758/pdf/v079p00391.pdf

[12] Health Canada. Guidelines for Canadian Drinking Water Quality: Guideline Technical Document - Arsenic. Federal-ProvincialTerritorial Committee on Drinking Water of the Federal-Provincial-Territorial Committee on Health and the Environment. 2006. [Cited 27th April 2017]. Available from: http://www.healthycanadians.gc.ca/publicati ons/healthy-living-vie-saine/water-arseniceau/alt/water-arsenic-eau-eng.pdf

[13] IPPH Knowledge translation - ClHR [Internet]. Cihr-irsc.gc.ca. 2014 [Cited 27th April 2017]. Available from: http://www.cihrirsc.gc.ca/e/27155.html

[14] Sara V. Flanagan and Robert G. Marvinney. Influences on domestic well water testing behavior in a Central Maine area with frequent groundwater arsenic occurrence. Sci Total Env. 2015;100(2):130-4. [Cited 27th April 2017]. Available from: https://www.ncbi.nlm.nih.gov/pmc/articles/P MC4245378/ 
[15] Chappells H, Campbell N, Drage J, Fernandez C V., Parker L, Dummer TJB. Understanding the translation of scientific knowledge about arsenic risk exposure among private well water users in Nova Scotia. Sci Total Environ [Internet]. 2015;505:1259-73. [Cited 27th April 2017]. Available from: http://dx.doi.org/10.1016/j.scitotenv.2013.12 .108

[16] Boyle KJ, Kuminoff N V., Zhang C, Devanney M, Bell KP. Does a property-specific environmental health risk create a "neighborhood" housing price stigma? Arsenic in private well water. Water Resour Res. 2010;46(3). [Cited 27th April 2017]. Available from:

http://onlinelibrary.wiley.com/doi/10.1029/2 009WR008074/full

[17] Standards Council of Canada. CAN-P-4E ISO/IEC 17025:2005 Corr 1:2006 Requirements and guidance - Accreditation. [Cited 27th April 2017]. Available from: https://www.scc.ca/en/about-

scc/publications/criteria-and-procedures/canp-4e-iso-iec-17025-2005-corr-1-2006

[18] Standards Council of Canada. CAN-P-1585 - Requirements for the Accreditation of Environmental Testing Laboratories, Program Specialty Area - Environmental Testing (PSAET) - December 2008. [Cited 27th April 2017]. Available from: https://www.scc.ca/en/aboutscc/publications/criteria-and-procedures/canp-1585-requirements-for-accreditationenvironmental-testing-laboratories-programspecialty-area
[19] George CM, Smith AH, Kalman

DA, Steinmaus CM. Reverse Osmosis Filter Use and High Arsenic Levels in Private Well Water. Archives of environmental \& occupational health. 2006;61(4):10.3200/AEOH.61.4.171175. [Cited 27th April 2017]. Available from: https://www.ncbi.nlm.nih.gov/pmc/articles/P MC3849398/

[20] Arsenic in Drinking Water [Internet]. Healthlink BC 2016. [Cited 27th April 2017]. Available from: https://www.healthlinkbc.ca/healthlinkbcfiles/arsenic-drinking-water

[21] De Groot J, Review and cost analysis of reverse osmosis and ultrafiltration (2013). [Cited 27th April 2017]. Available from: http://digitalcommons.calpoly.edu/cgi/viewc ontent.cgi?article $=1090 \&$ context $=\mathrm{dscisp}$

[22] Perelló G, Martí-Cid R, Llobet JM, and Domingo JL. Effects of Various Cooking Processes on the Concentrations of Arsenic, Cadmium, Mercury, and Lead in Foods J. Agric. Food Chem., 2008, 56 (23), pp 11262-11269. [Cited 27th April 2017]. Available from: http://pubs.acs.org/doi/full/10.1021/jf802411 q\#citing

Gordon D, Zubel M, Choquette B, Heacock H. Follow-Up Study of Well Users Affected by Groundwater Arsenic in the Surrey-Langley Area. BCIT Environmental Health Journal. 2017 